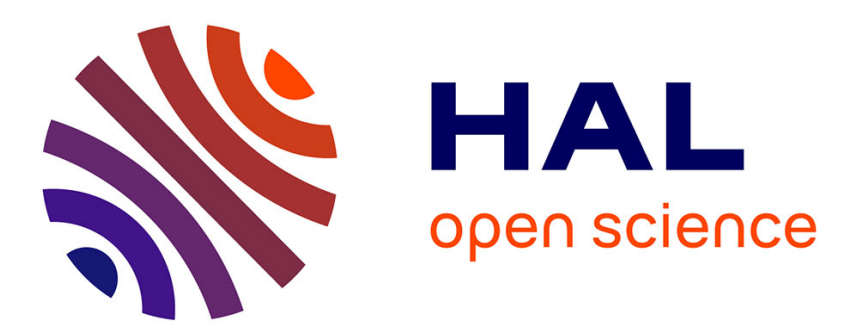

\title{
Do previous good deeds to a third party make people more tolerant of bad deeds against them? An experimental investigation \\ Christel Ndodjang Ngantchou, Gilles Grolleau, Lisette Ibanez
}

\section{To cite this version:}

Christel Ndodjang Ngantchou, Gilles Grolleau, Lisette Ibanez. Do previous good deeds to a third party make people more tolerant of bad deeds against them? An experimental investigation. Economics Letters, 2013, 121 (3), pp.364-368. 10.1016/j.econlet.2013.09.015 . hal-01485485

\author{
HAL Id: hal-01485485 \\ https://hal.science/hal-01485485
}

Submitted on 8 Mar 2017

HAL is a multi-disciplinary open access archive for the deposit and dissemination of scientific research documents, whether they are published or not. The documents may come from teaching and research institutions in France or abroad, or from public or private research centers.
L'archive ouverte pluridisciplinaire HAL, est destinée au dépôt et à la diffusion de documents scientifiques de niveau recherche, publiés ou non, émanant des établissements d'enseignement et de recherche français ou étrangers, des laboratoires publics ou privés. 


\title{
Do previous good deeds to a third party make people more tolerant of bad deeds against them? An experimental investigation
}

\author{
P. Ndodjang ${ }^{\mathrm{a}, \mathrm{b}}, \mathrm{G}$. Grolleau ${ }^{\mathrm{a}, \mathrm{c}}$, L. Ibanez ${ }^{\mathrm{d}, *}$ \\ a Montpellier SupAgro, UMR1135 LAMETA, F-34000 Montpellier, France \\ ${ }^{\mathrm{b}}$ Centre for Population, Poverty and Public Policy Studies, Luxembourg \\ ${ }^{c}$ LESSAC, Burgundy School of Business, France \\ d INRA, UMR1135 LAMETA, F-34000 Montpellier, France
}

\section{H I G H L I G H T S}

- Modified ultimatum game with performed good deed towards third party by proposer.

- We show that previous good deeds make responders more tolerant to unfair proposals.

- Individuals are not only influenced by payoffs or equity issues, but also by past deeds.

\section{A R T I C L E I N F O}

\section{Article history:}

Received 8 July 2013

Received in revised form

2 September 2013

Accepted 13 September 2013

Available online 21 September 2013

\section{JEL classification:}

C91

D03

\section{Keywords:}

Experiment

Licensing

Reciprocity

Social norms

Punishment

\begin{abstract}
A B S T R A C T
How do people react to a mix of good deeds to a third party and bad deeds against them? A modified ultimatum game shows that previous good deeds make responders substantially more tolerant to unfair proposals.
\end{abstract}

(C) 2013 Elsevier B.V. All rights reserved.

\section{Introduction}

We frequently see individuals performing good and bad deeds. The theory of reciprocity predicts that 'good deeds' are usually rewarded while bad ones are punished, even if it is costly for the individual (Falk and Fischbacher, 2006; Rabin, 1993). Nevertheless, little is known on people's reactions when they face a mix of good and bad deeds, especially if their reaction is costly for them. We explore how individuals behave when they face a bad deed perpetrated by someone who has previously performed a good deed directed not to them, but to a third party. Does the 'victim'

\footnotetext{
* Correspondence to: 2, place Pierre Viala, Bât. 26, 34060 Montpellier Cedex 1, France. Tel.: +330499613013; fax: +330467545805.

E-mail address: ibanez@supagro.inra.fr (L. Ibanez).
}

simply ignore this previous good deed and react to the bad deed? Or does he take into account the virtuous act, and if so, what will be the overall effect? For example, will consumers be less willing to boycott a polluting firm if this firm devotes a part of its profits to fight hunger in the world? In the same vein, does a firm proposing cause-related products make consumers more tolerant to price increases? To fill this gap, we designed a modified ultimatum game where the proposer first performs a good deed towards a third party. We investigate whether the responder is more or less tolerant to a proposer's unfair sharing because of his previous good deed to a third party.

The originality of our paper is at least twofold. First, we consider in a coherent framework how people react to a mix of good and bad deeds, when they are victims of bad deeds. Second, we test the predictions of licensing others' past moral behavior theory that states that people who commit a bad deed are judged less harshly 
when they have previously performed a good deed. The remainder of this note is organized as follows. Section 2 provides an overview of related literature and presents our main behavioral hypothesis. Section 3 exposes the experimental strategy. The results are presented and discussed in Section 4. Section 5 concludes and draws some policy implications.

\section{Overview of related literature and hypotheses}

Psychologists frequently describe people's behavior as being influenced by a strong need to maintain consistency between one's actions, or even feelings, and certain values, long term goals, or identities they seek to uphold (Benabou and Tirole, 2006). Nevertheless, individuals' actions do not always seem consistent. For instance, one will refrain from eating an unhealthy main course and will feel himself licensed to choose a sweet dessert. Subsequent actions that are inconsistent with prior deeds can be due to the influence of these prior deeds. It is precisely what the moral licensing theory predicts: prior good deeds can affect individuals' future behavior and liberate them to act in ways that are not consistent with their prior actions. ${ }^{1}$ Some studies provide empirical support that past good deeds can license individuals to engage in socially undesirable behaviors (see Clot et al., in press). For example, Khan and Dhar (2006) showed that preferences for a luxury product were significantly higher for individuals who imagined performing a charitable action first (57.4\%) than for others who do not (27.7\%). In the same vein, Sachdeva et al. (2009) found that writing a self-relevant story containing positive words referring to fairness and carefulness reduces people's donation (up to $\$ 10$ ) to a charity of their choice ( $\$ 5.30$ for those who wrote a negative story versus $\$ 1.07$ for those who wrote a positive story). In another experiment, Mazar and Zhong (2010) showed that purchasing green products increased antisocial behaviors, such as lying and stealing.

From a conceptual viewpoint, the self-licensing literature suggests two mechanisms that can explain why good deeds can lead to subsequent bad deeds. First, good deeds reframe bad deeds. In the so-called moral credentials model, good deeds change the meaning of subsequent behaviors, which are not perceived as bad deeds at all. For instance, using a low-energy light bulb can unconsciously lead the individual not to switch off lights when leaving a room, thinking that he does not waste energy because of the energy-saving bulb. Second, good deeds balance bad ones out and generate moral credits (Effron and Monin, 2010; Miller and Effron, 2010). In the moral credits model, good deeds establish moral credits like deposits in a bank account that can be 'withdrawn' to 'purchase' the right to perform bad deeds (Effron and Monin, 2010; Krumm and Corning, 2008; Merritt et al., 2010; Miller and Effron, 2010). In short, licensing theory predicts that individuals, like people who observe them, are sometimes willing to license morally dubious behaviors based on individuals' prior moral behavior (Merritt et al., 2010).

The theory of reciprocity is a frequently used framework to analyze how individuals react to others' behaviors. This theory predicts that good deeds are usually rewarded while bad ones are punished. This theory has been refined, for instance, by distinguishing direct versus indirect reciprocity or altruistic versus strong reciprocity. Fehr et al. (2002) and Fehr and Fischbacher (2004) shed light on the difference between strong reciprocity and altruistic reciprocity. An altruistic reciprocator conditions his behavior on the previous behavior of another actor. He is willing

\footnotetext{
1 Sachdeva et al. (2009) provide evidence that this phenomenon also occurs in the opposite direction. Indeed, because of previous bad deeds, individuals can be more likely to undertake good deeds, that is, moral cleansing.
}

to help another actor even if it is costly because he expects long term net benefits. On the other hand, a person is a strong reciprocator if he is willing to sacrifice resources to reward fair and to punish unfair behavior even if this is costly and provides neither present nor future material rewards for him (Fehr et al., 2002). Strong reciprocity conditions behavior depending on the respect or violation of social norms by others. The model of Falk and Fischbacher (2006) also predicts that there are two aspects underlying the evaluation of the kindness of an action: the consequences of the considered action, and the agent's underlying intentions. Nevertheless, reciprocity models do not offer clear predictions of a victim's behavior when the author of the bad deed has previously performed a good deed in favor of a third party. We call this situation a 'reciprocity dilemma' because it mixes direct and indirect reciprocity, negative and positive reciprocity. Predicting the overall effect is unclear. In our above-mentioned example, if a responder is an altruistic reciprocator, his reaction will be to punish the proposer for the unkind behavior towards him. However, strong reciprocity predicts that a responder could reward a proposer because of his good deed towards a third party in order to reward the respect of some social norms.

The inequity aversion developed by Fehr and Schmidt (1999) constitutes an alternative framework to predict individuals' behavior when they interact with others. This theory asserts that individuals are averse to inequity and are willing to sacrifice resources to reduce it. Unlike predictions of traditional economics, which stipulate that agents maximize their absolute payoff regardless of their past actions or others' choices, our hypothesis is that past actions matter and influence the willingness of individuals to reduce inequity.

\section{Experimental design}

We conducted a paper and pencil experiment with students and staff from the universities of Montpellier and Nîmes (south of France). 162 students (from a wide range of disciplines) and staff (mean age $=36.6$ years and $78 \%$ females) participated in this experiment. Participants were members of the university chorale and the experiment was run at the end of weekly rehearsals. All subjects were unfamiliar with experimental economics. They received a show-up-fee of $€ 5$. The instructions were read aloud by the monitor and were also available on a written sheet. Participants were asked not to talk during the experiment; otherwise they would be excluded from the drawing lots. $A € 30$ prize was available to every pairs of participants chosen through drawing lots ( 1 winner per 15 players). ${ }^{2}$ Before inviting the subjects to make their decisions, the monitor asked them whether they had well understood the rules of the game.

Our experiment consists of a one-shot ultimatum game with two treatments (see Fig. 1): a between-subject experiment with a Good Deed Treatment (GDT) where the proposer has previously performed a good deed and a Control Treatment (CT) in which the proposer did not. The GDT included two stages. In the first stage, the proposer has the possibility to engage himself into a prosocial action towards a third party. ${ }^{3}$ More precisely, the proposer has to

\footnotetext{
2 A similar method is used in Exadaktylos et al. (2013).

3 The proposer has also been given the possibility to refuse to help the association as we aimed to induce a voluntary good deed. There was only one proposer who did not offer to volunteer for the charity in the good deed treatment (GDT) and she/he has been deleted from the database. Consequently, the responders faced proposals only from people who stated their willingness to volunteer in favor of the charity. As suggested by a referee, an insightful extension is about the effect of refusing to perform the good deed or accepting but on responders' reactions. In this case, we might expect a strong negative reaction from responders to unfair offers. Unfortunately, we cannot investigate this interesting issue with our data.
} 
CONTROL TREATMENT

(CT)

$\begin{array}{ll}\text { 1st } & \begin{array}{l}\text { No information on } \\ \text { behavior of the } \\ \text { proposer }\end{array}\end{array}$

\section{GOOD DEED TREATMENT}

(GDT)

The responder is informed about the voluntary good deed performed by the proposer

2nd
Stage

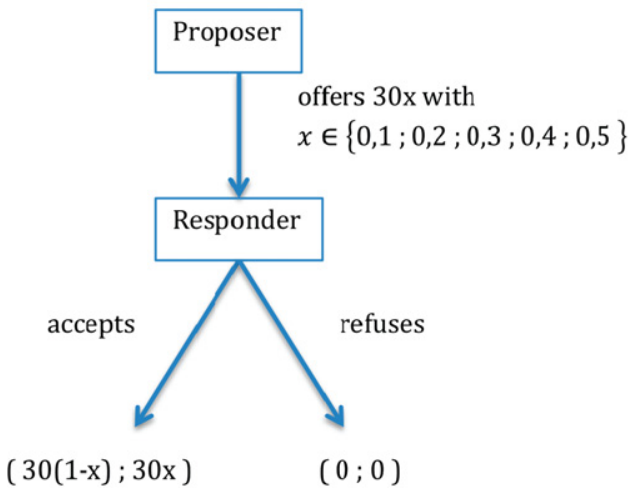

Fig. 1. Experimental design.

choose the number of hours between 0 and 3 that he is willing to spend to help a charity namely the "Restos du Coeur". This association is the most popular in France, which aims to distribute food packages and hot meals to people in need. The individual was also informed that in a second stage he will play with another participant who will be informed about his choice regarding the Restos du Coeur cause. This stage of the experiment was based on an oral commitment without any enforcement device (for a similar method, see for instance Khan and Dhar, 2006). According to Akerlof (2005), norms of appropriate behaviors differ across space and time. To overcome this potential bias, responders of GDT were asked to appreciate the action of proposer on a Likert 9-point scale (from $1=$ bad deed to $9=$ good deed). Overall, 4 sessions of about 15 min each were run. Participants were randomly assigned to the control treatment $\left(\mathrm{N}_{\mathrm{CT}}=75\right)$ or the good deed treatment $\left(\mathrm{N}_{\mathrm{GDT}}=\right.$ 72). ${ }^{4}$ Proposers were in another room playing simultaneously with responders. $^{5}$

In the second stage, we performed a reduced ultimatum game, using the strategy method in which responders decide on a limited range of offers, that are $50 \%, 40 \%, 30 \%, 20 \%$, and $10 \%$ of the proposer's endowment. The responders in GDT were informed that the proposer has decided to devote some time to help "Restos du Coeur" without stipulating the number of hours. Following the contributions of Güth et al. (1982) and Falk and Fischbacher (2006) we considered that proposals lower than $40 \%$ of the endowment are unfair proposals and can be considered as 'bad deeds'. In an ultimatum game, the recipient can punish the proposer for "cheating" on an implicit social norm of reciprocal sharing by rejecting the proposer's offer (Hoffman et al., 2008). Consequently, we compared the responders' reaction to unfair proposals between these two treatments. This strategy method allowed us to elicit the minimum share that responders are willing to accept. The responders were also asked to state the minimum amount that they were willing to accept. According to the licensing others'

\footnotetext{
4 Because of inconsistent answers, three participants were eliminated.

5 We designed the experiment in such a way that proposers were only useful for the drawing lots in our ultimatum game. Given that proposals and responses were elicited through the strategy method, we needed proposers mainly for earnings.
}

past moral behavior theory, we expect a difference in acceptance rates for unfair offers between the two treatments. In other words, responders in the GDT will accept more unfair offers than responders in the $\mathrm{CT}$. A full version of experimental instructions can be found in Appendix.

At the end of the two stages we selected pairs of winners $A$ and $C$ and they were paid according to the game rules. Formally, each set of two winning players was paid if the proposer's offer was higher or equal to the minimal share accepted by responder. The average gain for each winner was about $€ 15$.

\section{Results and discussions}

We focused only on responder's behavior, resulting from the second stage in the treatments CT and GDT. The number of hours chosen by the proposer was between 0 and 2 with an average of 1.36 . The average of proposals was $€ 12.33$ over $€ 30$. These data were only useful for matching and paying proposers and responders after drawing of lots.

First, we estimated how responders evaluate the voluntary action of the proposer towards "Restos du Coeur". The average score for proposer's volunteering given by the responder is equal to 8.07 on a Likert 9-point scale. This supports the insight that responders (in the GDT) considered the volunteering of proposers as a good deed. Responders in the control treatment were not concerned by this step.

Fig. 2 shows the mean of minimum accepted offers that responders of CT and GDT are willing to accept. In the good deed treatment this amount is $€ 4.21$ against $€ 6.55$ in the Control group. This corresponds respectively to $14 \%$ and $21.8 \%$ of the proposer's endowment. In other words, the minimum acceptable offer for responders in the Good Deed Treatment is less than the minimum acceptable offer in the Control Treatment. This difference is significant ( $p=0.004$ ) and supports the insight regarding the licensing effect of a previous good deed even if the beneficiary is a third party.

Fig. 3 and Table 1 provide the acceptance rates of proposers' offers by responders. First, acceptance rates in the control group (CT) are consistent with results of previous studies on the ultimatum game (Andrade and Ariely, 2009; Falk and Fischbacher, 2006; Güth et al., 1982). There is a decrease in acceptance rates 


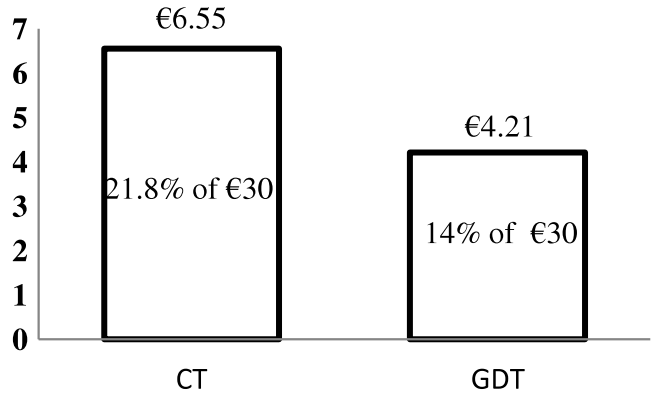

Mean of minimum accepted offers

Fig. 2. Mean of minimum accepted offers under CT and GDT.

\section{CT GDT}

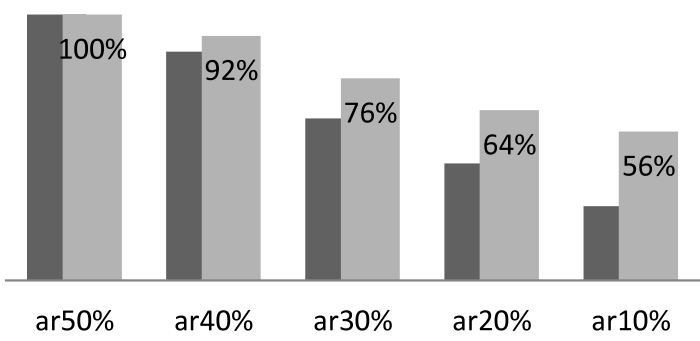

ar: acceptance rate of the offer $\mathrm{X} \%$

Fig. 3. Acceptance rates of various offers between CT and GDT.

Table 1

Acceptance rates of a given percentage of the proposer's endowment by responders in CT and GDT.

\begin{tabular}{lllllll}
\hline & ar50\% & ar40\% & ar30\% & ar20\% & ar10\% & $\begin{array}{l}\text { Mean of } \\
\text { minimum } \\
\text { accepted offers } \\
\text { (in €) }\end{array}$ \\
\hline CT & $100 \%$ & $86 \%$ & $61 \%$ & $44 \%$ & $28 \%$ & 6.55 \\
GDT & $100 \%$ & $92 \%$ & $76 \%$ & $64 \%$ & $56 \%$ & 4.21 \\
$P>0.05$ & 1 & 0.2548 & 0.052 & 0.017 & 0.001 & 0.004 \\
\hline
\end{tabular}

with lower offers of proposers and unfair offers lead to higher rejection rates.

Second, except for equal sharing, the acceptance rate of proposals by responders is higher in GDT compared to CT (Table 1). Responders in the GD treatment accept on average significantly more unfair offers than responders of the control group. For instance, if only $10 \%$ of the proposer's endowment is offered, the acceptance rate is $28 \%$ in the control treatment and doubles (56\%) in the good deed treatment. Even if this pattern needs to be verified in future experiments, the lower the offer, the stronger the compensation effect of a previous good deed directed towards a third party. These findings support that previous good deeds matter. Our findings give support for licensing others' past moral behavior theory predictions compared to predictions from traditional economics or inequity aversion models. Even if the responder is the victim of a bad deed, he is more tolerant to unfair offers from a player who stated doing a good deed directed at a third party than towards a proposer who has not done any good deed before.

\section{Conclusion}

Our research contributes to the literature that focuses on the role of moral self-licensing on behavior, and more precisely on licensing others' past moral behaviors. The findings support that a proposer's previous good deed to a third party makes responders substantially more tolerant to unfair proposals. Responders, being informed on a voluntary good deed performed previously by the proposer, accept on average significantly more unfair offers than responders in the control group. Moreover, the tendency to accept more easily offers in the good deed treatment compared to the control treatment becomes more pronounced when offers become more unfair. Unlike traditional economics and inequity aversion predictions, individuals are not only influenced by their payoff or equity issues, but also by past deeds.

Good deeds can also be performed for strategic reasons that can be consistent with self-interest maximization. For instance, some firms could strategically perform prosocial activities with the aim of making consumers more tolerant towards their bad deeds. For example, firms can help good causes through donations or cause-related-products to make consumers more tolerant to price increase (Grolleau et al., 2011).

Nevertheless, several dimensions of licensing others' past moral behavior deserve more academic attention. A natural issue is related to the robustness of our results in various settings. For instance, our experiment was done with a chorale group, which means they could be quite familiar with each other. In addition, we used limited monetary incentives. These potential interaction effects may have influenced our findings. For instance, Leider et al. (2009) provide experimental evidence that social connections increase prosocial giving. So it is important to explore whether participants behave differently or not if they are not so connected and if they face stronger monetary incentives. Moreover, does the mechanism remain when the individual performed first a bad deed, making others less willing to enjoy his subsequent good deed? Does the money origin (e.g., windfall versus earned) affect the licensing effect and how? Is there a temporal dimension regarding the effect of past deeds, e.g. does the effect of past deeds fade with time? In another direction, how do people track accountability of good and bad deeds? We believe that the issues we touch in this contribution are ripe for further exploration.

\section{Acknowledgments}

The authors are very grateful to Naoufel Mzoughi, Sophie Clot, Angela Sutan, an anonymous referee and participants of the IMEBE 2013 Conference and ASFEE 2013 Meeting who provided valuable feedback. We also thank Martin Koums, Fosso Manuella and MarieGaelle Njambé and David Shapiro for research assistance and all participants in Montpellier and Nîmes.

\section{Appendix. Experimental instructions for responders (Trans- lated from French)}

Welcome. You are going to participate in an experiment about decision making. There is no right or wrong answer. The session will last about fifteen minutes. Your answers will be treated anonymously. During this experimental session, you are requested to make decisions and you can earn money. Please note that during the experiment communication is not allowed. If you have questions, please raise your hand. We will answer your questions in private.

You have received a closed envelope containing a questionnaire. This questionnaire is intended for the study of your decisionmaking. Please answer honestly.

First stage: (Good deed treatment only)

During this questionnaire you will be randomly matched with another participant. This participant had voluntarily stated that he was willing to devote time to help the association "Restos du Coeur" to distribute meals to people in need. 
What do you think of this participant? Please, evaluate whether this behavior constitutes a bad or a good deed on the following scale:

\begin{tabular}{c|c|c|c|c|c|c|c|c|}
\hline 1 & 2 & 3 & 4 & 5 & 6 & 7 & 8 & 9 \\
\hline Bad deed
\end{tabular}

Second stage: (Good deed and Control treatments)

You will earn money according to the procedure defined in the sheet if you are chosen by lots ( 1 winning lot for every 15 participants). Your identity and that of the other participant will remain anonymous. This participant received an amount of money $€ 30$, to share with you. If you accept the offer that she/he will propose to you, the transaction is carried out, and each of you will get the amount specified by him. If you reject his offer, neither she/he nor you get anything.

Please indicate whether you agree or not with an amount included in each of the following ranges:

- An amount between $€ 15$ and 13 :

I accept $\square$

I refuse $\square$

- An amount between $€ 12$ and 10 :

- An amount between $€ 5$ and 3:

- An amount between $€ 2$ and 0 : I accept $\square$ I refuse $\square$ refuse $\square$

-What is the minimum offer that you are willing to accept?

\section{References}

Andrade, E., Ariely, D., 2009. The enduring impact of transient emotions on decision making. Organ. Behav. Hum. Decis. Process. 109, 1-8.

Akerlof, G., 2005. Identity and the economics of organizations. J. Econ. Perspect. 19, 9-32.
Benabou, R., Tirole, J., 2006. Incentives and Prosocial Behavior. Am. Econ. Rev. 96 (5), 1652-1678

Clot, S., Grolleau, G., Ibanez, L., Ndodjang, P., 2013. L'effet de compensation morale ou comment les "bonnes actions" peuvent aboutir à une situation indésirable. Rev. Économique (in press).

Effron, D., Monin, B., 2010. Letting people off the hook: when do good deeds excuse transgressions?. Personal. Soc. Psychol. Bull. 36 (12), 1618-1634.

Exadaktylos, F., Espin, A.M., Branas-Garza, P., 2013. Experimental subjects are not different. Sci. Rep. 3, 1213.

Falk, A., Fischbacher, U., 2006. A theory of reciprocity. Games Econom. Behav. 54, 293-315.

Fehr, E., Schmidt, K.M., 1999. A theory of fairness, competition, and cooperation. Quart. J. Econ. 114, 817-868.

Fehr, E., Fischbacher, U., Gächter, S., 2002. Strong reciprocity, human cooperation, and the enforcement of social norms. Hum. Nat. 13 (1), 1-25.

Fehr, E., Fischbacher, U., 2004. Third-party punishment and social norms. Evol. Hum. Behav. 25 (2), 63-87.

Grolleau, G., Ibanez, L., Moulla, S., 2011. Éléments d'analyse économique des produits partage. Rev. Int. de Droit Économique 25 (2), 239-256.

Güth, W., Schmittberger, R., Schwarze, B., 1982. An experimental analysis of ultimatum bargaining. J. Econ. Behav. Organ. 3 (4), 367-388.

Hoffman, E., McCabe, K., Smith, V., 2008. Reciprocity in ultimatum and dictator games. An introduction. Handb. of Exp. Econ. Results. 411-416.

Khan, U., Dhar, R., 2006. Licensing effect in consumer choice. J. Mark. Res. 43 (2), 259-266.

Krumm, A., Corning, A., 2008. Who believes us when we try to conceal our prejudices? The effectiveness of moral credentials with in-groups versus outgroups. J. Soc. Psychol. 148 (6), 689-710.

Leider, S., Möbius, M.M., Rosenblat, T., Do, Q.A., 2009. Directed altruism and enforced reciprocity in social networks. The Q J. of Econ. 124 (4), 1815-1851.

Mazar, N., Zhong, C., 2010. Do green products make us better people?. Psychol. Sci. 21 (4), 494-498.

Merritt, A., Effron, D., Monin, B., 2010. Moral self-licensing: when being good frees us to be bad. Soc. Personal. Psychol. Compass 4 (5), 344-357.

Miller, D., Effron, D., 2010. Psychological License: when it is needed and how it functions. Adv. Exp. Soc. Psychol. 43, 115-155.

Rabin, M., 1993. Incorporating fairness into game theory and economics. Am. Econ. Rev. 83, 1281-1302.

Sachdeva, S., Iliev, R., Medin, D., 2009. Sinning saints and saintly sinners. Psychol. Sci. 20 (4), 523-528. 